\title{
Clinical evaluation of a trabecular microbypass stent with phacoemulsification in patients with open-angle glaucoma and cataract
}

This article was published in the following Dove Press journal:

Clinical Ophthalmology

14 September 2016

Number of times this article has been viewed

\section{Tanner J Ferguson' \\ John P Berdahl ${ }^{2}$ \\ Justin A Schweitzer ${ }^{2}$ \\ Ramu G Sudhagoni'}

'Sanford School of Medicine, University of South Dakota, Sanford School of Medicine, Sioux Falls, SD, USA; ${ }^{2}$ Vance Thompson Vision, Sioux Falls, SD, USA
Correspondence: Tanner J Ferguson Vance Thompson Vision, 3I0I W 57th St, Sioux Falls, SD 57108, USA

Tel +l 7I28996I53

Email tannerferguson@me.com
Purpose: To evaluate the safety and efficacy of the iStent trabecular microbypass stent in combination with cataract surgery in patients with open-angle glaucoma (OAG).

Methods: Retrospective, consecutive case series from October 2012 to December 2015 with no exclusion criteria. The series comprised of 350 eyes with OAG and cataract. Data were collected both preoperatively and postoperatively at day 1 week 1 , months $1,3,6,12,18$, and 24. Data included intraocular pressure (IOP), number of glaucoma medications, visual acuity, the incidence of postoperative IOP pressure spikes of greater than $\geq 15 \mathrm{mmHg}$ at any time point, and need for additional surgery.

Results: The mean preoperative IOP was $19.13 \pm 6.34 \mathrm{mmHg}$. At 2 years postoperation, mean IOP was $15.17 \pm 3.53 \mathrm{mmHg}(P<0.0001)$. The mean number of glaucoma medications was $1.19 \pm 1.00$ preoperatively and $0.61 \pm 0.96(P<0.0001)$ at 2 years postoperation. At 1 day postoperatively, 31 eyes $(12.4 \%)$ experienced an IOP increase of $15 \mathrm{mmHg}$ above their baseline IOP that responded to topical therapy. Two patients required additional tube shunt surgery.

Conclusion: The insertion of the iStent trabecular microbypass stent in combination with cataract surgery effectively lowers IOP in OAG patients. The magnitude of IOP reduction was more significant in patients with higher preoperative pressure. Medication use was also significantly reduced postoperatively. The safety profile appears favorable with a low rate of IOP spikes and only two eyes $(<1 \%)$ requiring additional surgery.

Keywords: iStent, trabecular microbypass stent, glaucoma, microinvasive glaucoma surgery, open-angle glaucoma, glaucoma surgery

\section{Introduction}

Glaucoma is a progressive optic neuropathy that will affect almost 80 million people worldwide by $2020 .{ }^{1}$ The most common form of the disease, open-angle glaucoma (OAG), represents nearly $75 \%$ of the projected 80 million victims worldwide. Glaucoma is the second leading cause of irreversible blindness, and by 2020, almost 6 million people with OAG will have bilateral blindness. ${ }^{1}$

Glaucoma is typically characterized by increased intraocular pressure (IOP) levels, progressive cupping of the optic nerve, and visual field loss. In OAG, IOP levels rise leading to decreased aqueous outflow through the trabecular meshwork. Since IOP is the only modifiable risk factor associated with the disease, glaucoma is managed by lowering IOP to slow the progression of the disease. To achieve a sustained reduction in IOP, there are several different treatment options available depending on the stage of the disease. In early stages of the disease, ocular hypotensive drugs have traditionally been considered the first-line treatment. However, because of issues with tolerability 
and proper administration of the drugs, pharmacotherapy can be challenging and often results in poor compliance. ${ }^{2,3}$ If a significant reduction in IOP is not achieved with these methods, there are other surgical options including trabeculectomy, tube shunts, and cylcoablative procedures. Although these operative treatments have been shown to lower IOP significantly, there are considerable risks associated with these options. ${ }^{4,5}$

Cataract surgery alone has been shown to produce a reduction in IOP. ${ }^{6,7}$ Consequently, it remains a safe and effective treatment option for those in the early stages of the disease, but it may not lower pressure adequately.

Because of the invasiveness and risks linked with current surgical treatment options, microinvasive glaucoma surgery (MIGS) procedures have emerged as a low-risk option for glaucoma management, particularly in $\mathrm{OAG}$, and are altering the glaucoma surgical profile. ${ }^{8}$ The MIGS procedures are performed $\mathrm{ab}$ interno and microincisional through the clear cornea free of conjunctival incisions. The procedures are minimally traumatic and very adaptable. ${ }^{9}$ The iStent (Glaukos Corp., Laguna Hills, CA, USA), the first US Food and Drug Administration approved ab interno MIGS device, is designed to serve as a bypass through the trabecular meshwork to improve physiological aqueous outflow and lower IOP. The titanium, L-shaped trabecular microbypass stent is $1.0 \mathrm{~mm}$ in length and $0.33 \mathrm{~mm}$ in height and is the smallest medical device ever approved by the US Food and Drug Administration. The iStent, in conjunction with cataract surgery, is implanted through the trabecular meshwork and into the Schlemm's canal with the assistance of a gonioprism. In anterior human segments in vitro, the iStent has been shown to be effective in reducing IOP and increasing aqueous outflow. ${ }^{10}$ Recently, several studies have demonstrated iStent implantation in conjunction with cataract surgery to be significantly more effective than cataract surgery alone in reducing IOP levels and use of glaucoma medications. ${ }^{11,12}$

The purpose of this study was to evaluate the safety and efficacy of the iStent in combination with cataract surgery in patients with OAG in a clinical practice setting. To collect data, a retrospective, consecutive case series was performed with no exclusion criteria to mimic the clinical use of the device and compare it to the more controlled and restrictive clinical trials.

\section{Methods}

\section{Study design}

Consecutive patients diagnosed with OAG and implanted with one iStent were included in the retrospective case series. OAG patients were narrowly defined as patients with primary OAG, normal tension glaucoma, and ocular hypertension. No cases were excluded. This study was designed to mimic typical clinical use of the device and compare the results to the more restrictive clinical trials currently published. This was a retrospective case series that collected data from procedures that had already occurred and was de-identified; therefore, no informed consent process was utilized. The University of South Dakota Institutional Review Board approved this study.

\section{Surgical technique}

After cataract removal and intraocular lens implantation using phacoemulsification (standard divide and conquer approach) through a clear corneal incision, the eye was rotated nasally and the head was rotated approximately $30^{\circ}$ away from the surgeon. The microscope was also rotated $30^{\circ}$ away from the surgeon, and the eye was left dilated with the cohesive viscolelastic used to insert the intraocular lens in the eye. A gonioprism was held on the cornea with the nondominant hand, and the trabecular meshwork was brought into focus using the microscope. The iStent, on a preloaded injector, was placed in the dominant hand and inserted through the clear corneal incision. A right stent was used in right eyes and a left stent was used in left eyes. The stent, on the tip of the inserter, was guided into the trabecular meshwork at a $20^{\circ}$ angle and advanced inferiorly. The stent was released and the shaft of the insertion device was used to nudge the stent inferiorly and push the heel of the device into the trabecular meshwork, and the secure placement of the device was confirmed by "strumming" the device with the injector tip in a posterior-to-anterior direction. If the stent was not properly secured, it was repositioned. The remaining viscoelastic was removed with irrigation and aspiration, including from behind the intraocular lens. If a hyphema or microhyphema was present at the end of surgery, it was removed as thoroughly as possible with irrigation and aspiration, although it was still common to see red blood cells in the anterior chamber at the end of the case. The cornea was hydrated and the pressure left in the physiological range. No pharmacological constricting agents or ocular hypotensive agents were used during or immediately after the procedure. All procedures were performed at the same site (Vance Thompson Vision, Sioux Falls, SD, USA) and by the same surgeon (JPB).

\section{Postoperative medications and follow-up}

Postoperatively, patients were prescribed antibiotics for 1 week, NSAIDs for 4 weeks, and steroid drops for 1 month, which started as QID and were tapered to BID after 1 week. Patients were kept on their preoperative ocular hypotensive medications for at least 1 week and until the patient's IOP was deemed clinically acceptable by the operating physician. As opposed to the more restrictive clinical trials, no specific guidelines were established to determine when to add or 
remove ocular hypotensive medications, and medication addition or removal was based on clinical judgment.

Preoperative data were used to establish a baseline, typically 1-2 weeks before the surgery. Postoperatively, data were collected from the following time points to compare to baseline: 1 day, 1 week, 1 month, 3 months, 6 months, 1 year, 18 months, and 2 years. At each time point, the data collected included IOP, number and type of medications used, and visual acuity. A consistent cohort group was also established to directly compare the eyes with 2-year postoperative data to baseline.

\section{Outcome measures and safety evaluation}

The primary outcome measure in the study was IOP by Goldmann applanation tonometry. Secondary outcome measures included the number and type of ocular hypotensive medications. Visual acuity outcomes were also collected and evaluated. To evaluate the safety of the procedure, the need for additional surgery was noted in addition to the incidence of IOP spikes $\geq 15 \mathrm{mmHg}$ at any time point postoperatively.

\section{Statistical analyses}

A parametric paired $t$-test procedure was used to determine the significance of the mean change in IOP from baseline to 24 months. A parametric paired $t$-test procedure was also used to determine the significance of the mean change in number of glaucoma medications from baseline to 24 months. All the statistical analyses in this paper were carried out using SAS software (Version 9.4, SAS Institute, Cary, NC, USA). An $\alpha$ level of 0.05 was considered statistically significant.

\section{Results}

\section{Subject demographics}

This retrospective case series evaluated 350 eyes from patients in a clinical setting. Of the 350, 217 were female and 133 were male. The mean age of the subjects in the study was 74.05 \pm 8.97 . All patients included in the study were previously diagnosed with $\mathrm{OAG}$, ranging from mild to moderate. These statistics are listed in Table 1. No identifying information was collected in the data collection process.

Table I The table illustrates baseline characteristics and subject demographics

\begin{tabular}{ll}
\hline Demographics and baseline characteristics \\
\hline Variable & Value \\
\hline Age, years (mean \pm SD) & $74.05 \pm 8.97$ \\
Gender (M/F) & $217 \mathrm{~F} / \mathrm{I} 33 \mathrm{M}$ \\
Study eye (OD/OS) & $170 \mathrm{OD} / \mathrm{I} 80 \mathrm{OS}$ \\
Number of glaucoma medications (mean $\pm \mathrm{SD})$ & $\mathrm{I} .19 \pm \mathrm{I} .00$ \\
Percentage of eyes with I+ medication $(\mathrm{s})$ & $72.6 \%(\mathrm{n}=254)$ \\
\hline
\end{tabular}

Abbreviations: SD, standard deviation; $M$, male; F, female; OD, right; OS, left.

\section{Efficacy}

\section{IOP and medications}

Figure 1 demonstrates the mean IOP and hypotensive medication use data collected at each visit. At baseline, the mean IOP was $19.13( \pm 6.34) \mathrm{mmHg}$ and the mean amount of hypotensive medications was $1.19( \pm 1.00)$. It is important to note that combination hypotensive medication drops were reported as two medications. At 6 months postoperatively, the mean IOP was $14.95 \pm 3.77$ and at 2 years postoperatively, $15.17 \pm 3.53 \mathrm{mmHg}(P<0.0001)$. The mean IOP at each time point is shown in Figure 1. At 2 years postoperatively, the amount of hypotensive drops was reduced by $49 \%$ from baseline to $0.61 \pm 0.96(P<0.0001)$. In addition, at 2 years postoperatively, $63 \%$ of patients were completely off hypotensive medication drops. These efficacy results are illustrated in Figure 2.

The consistent cohort group was established to directly compare the eyes with postoperative data at 2 years postoperative to baseline. This group was also used to demonstrate the magnitude of IOP reduction based on preoperative IOP. In this group, the mean IOP reduction was $>4 \mathrm{mmHg}$ at 2 years in comparison to baseline. In this group, medication reduction was $56 \%$ from baseline at 2 years postoperatively. At 6 months postoperatively, $62.2 \%$ of eyes were off medications with IOP $\leq 18 \mathrm{mmHg}$, and this proportion was similar at 24 months with $52 \%$ of eyes on zero medications with IOP $\leq 18 \mathrm{mmHg}$. These results are shown in Figure 3 . Furthermore, approximately $50 \%(n=44)$ of eyes in this group had postoperative data to 2.5 years, and the pressure reduction was sustained with a mean IOP $<16 \mathrm{mmHg}$. The results from this group are illustrated in Figure 4.

The results from this study also suggest a relationship between preoperative IOP and the magnitude of IOP reduction at 2 years postoperatively. Patients with preoperative IOP ranging from 22 to $25 \mathrm{mmHg}$ had a mean reduction of $7.69 \mathrm{mmHg}$, more than doubling the mean reduction seen in patients with $18-21 \mathrm{mmHg}(3.48 \mathrm{mmHg})$. If patients had a preoperative IOP $\geq 18 \mathrm{mmHg}, 96.7 \%$ experienced an IOP reduction. In patients with preoperative IOP greater than 26 , the mean IOP reduction was $11.28 \mathrm{mmHg}$. These results are demonstrated in Figure 5.

\section{Discussion}

The implantation of a microbypass stent in combination with cataract extraction has been shown to improve aqueous outflow through the trabecular meshwork into Schlemm's canal via ab interno placement of the device. The efficacy seen with the stent in this study is consistent with results described in previous work..$^{6,79}$ In this study, implantation 


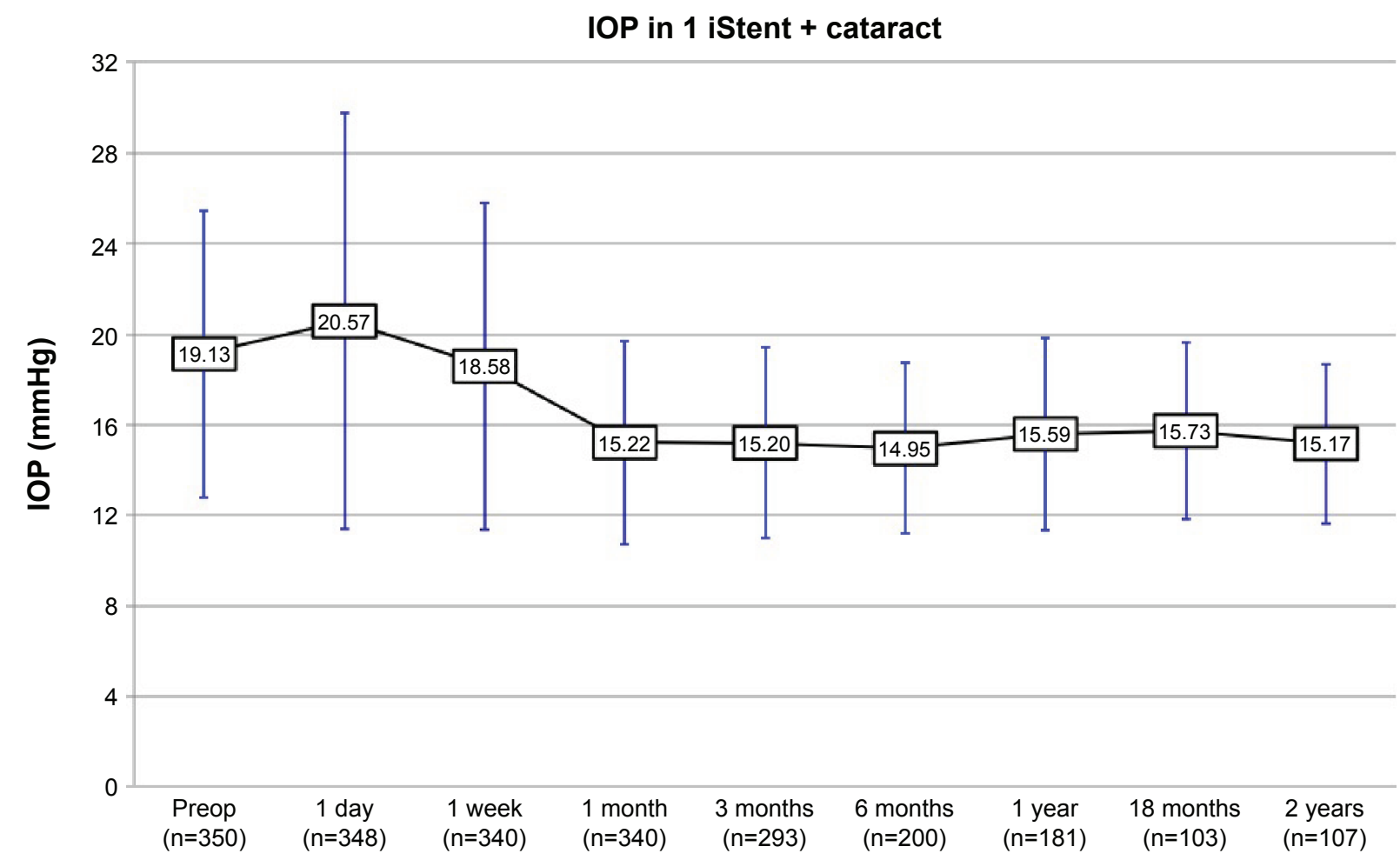

Figure I This graph demonstrates the mean IOP and SD at each time point.

Note: The bars represent SD.

Abbreviations: IOP, intraocular pressure; SD, standard deviation; Preop, preoperative.

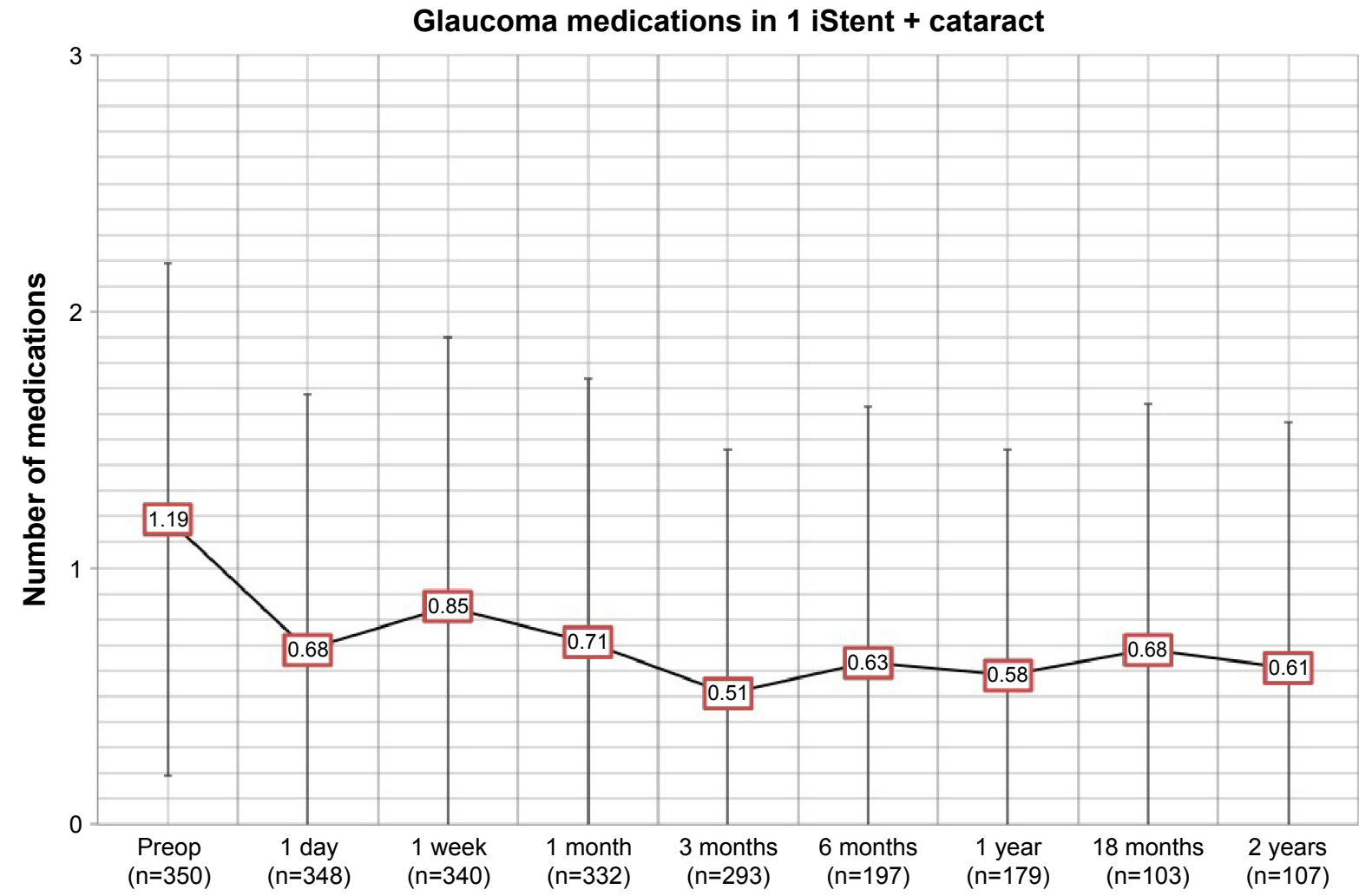

Figure 2 This graph demonstrates the mean amount of glaucoma medications at each visit from baseline to 24 months.

Note: The bars represent SD.

Abbreviations: SD, standard deviation; Preop, preoperative. 


\section{Consistent cohort - \% of eyes with \\ IOP $\leq 18 \mathrm{mmHg}+$ no medications}

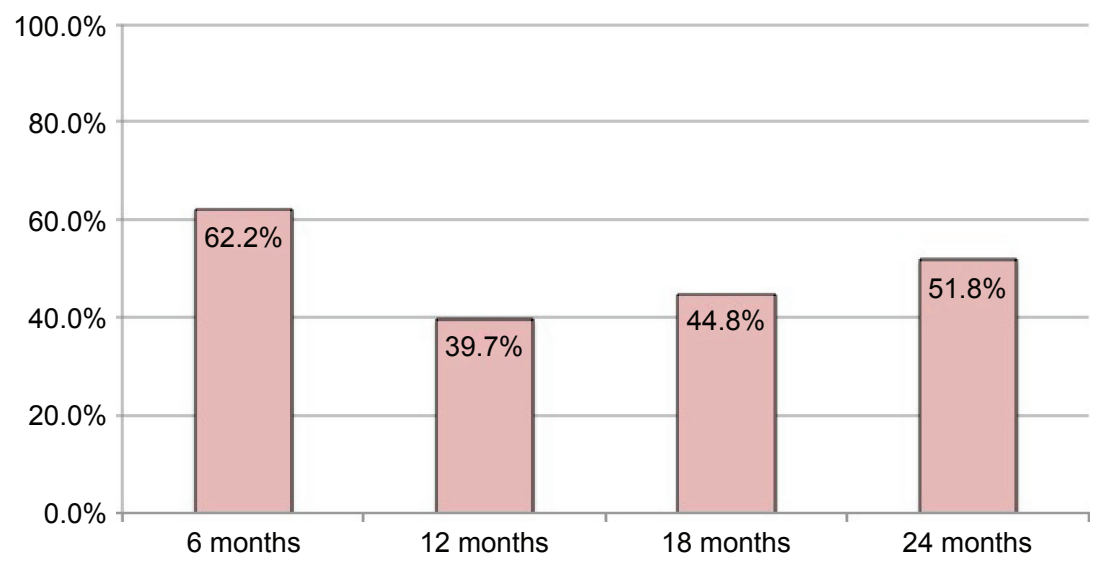

Figure 3 Proportion of eyes at months $6,12,18$, and 24 with IOP $\leq 18 \mathrm{mmHg}$ and off medications.

Abbreviation: IOP, intraocular pressure.

of the microbypass stent combined with cataract extraction resulted in a notable lowering of IOP and reduction in the use of ocular hypotensive medications 1 year postoperatively compared to cataract surgery alone. The Early Manifest Glaucoma Trial revealed that every $1 \mathrm{mmHg}$ decrease in IOP results in a decrease in the likelihood of disease progression. ${ }^{13}$ Slowing or halting disease progression is the goal of glaucoma treatment, and as the Early Manifest Glaucoma Trial revealed, even small decreases in IOP are clinically relevant. In this study, the mean decrease in the IOP was nearly $4 \mathrm{mmHg}$ at 6 months postoperatively, with a sustained reduction through 2 years postoperatively $(4.07 \mathrm{mmHg}$ ). Furthermore, approximately $50 \%$ of eyes $(n=43)$ had postoperative data to 2.5 years and IOP was maintained at $<16$ $\mathrm{mmHg}$. Studies have shown that phacoemulsification alone in patients with OAG can decrease IOP by $2 \mathrm{mmHg}$, and patients with a higher preoperative IOP show greater reduction in IOP than those with cataract surgery alone. ${ }^{14-16}$

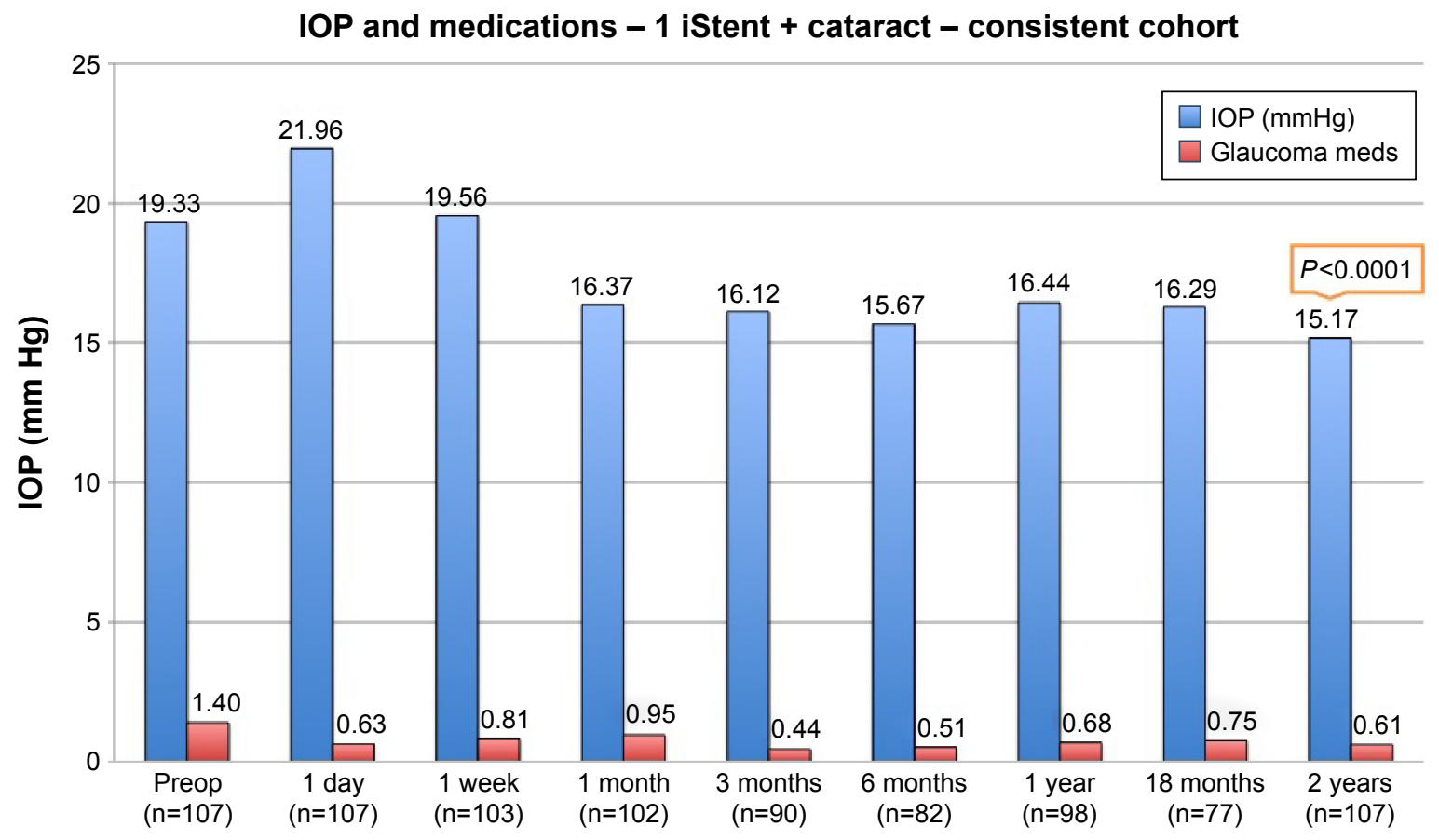

Figure 4 This graph demonstrates the mean IOP and hypotensive medication use collected at each time point in the consistent cohort group. Note: $P$-values from statistical analysis are shown at 2 years postoperatively to illustrate statistical significance.

Abbreviations: IOP, intraocular pressure; Preop, preoperative. 


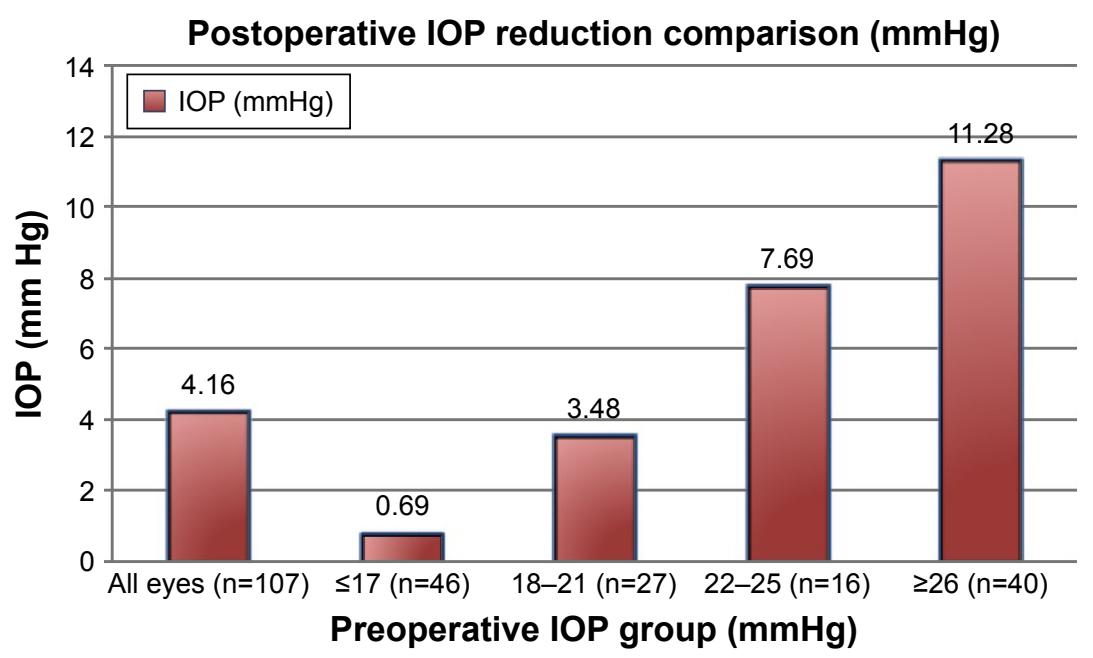

Figure 5 This graph demonstrates the relationship between preoperative IOP and magnitude of IOP reduction.

Note: To illustrate this, the preoperative pressures were stratified into four groups $(\leq 17,18-21,22-25$, and $\geq 26)$ and the mean IOP reduction for each group is shown. Abbreviation: IOP, intraocular pressure.

Although not directly comparable, our study demonstrated an additional reduction in IOP was achieved with the use of the microbypass stent combined with cataract surgery.

Our study was not without limitations. The study was an open-label and nonrandomized study. Diurnal IOP measurements were not collected. In addition, given that it was a retrospective study that relied on patient follow-up for data at each time point, postoperative data were missing for some patients at specific time points. However, to our knowledge, this study represents the largest sample size published to date and provides long-term follow-up data that support the safety and efficacy of the device. Furthermore, this study was a consecutive case series that did not utilize inclusion or exclusion criteria so as to mimic clinical use of the device and compare it to the more restrictive clinical trials. This study used data from procedures performed by one surgeon (JPB) at a single site. There was no significant difference in data between the early and later procedures, suggesting the surgeon did not likely experience a noticeable learning curve.

The results shown in Figure 3 suggest a correlation between preoperative IOP and the degree of IOP reduction seen at 2 years postoperatively. Patients with a higher preoperative IOP achieved a significantly greater mean reduction, with eyes of preoperative IOP of $26 \mathrm{mmHg}$ or greater achieving a mean reduction of $11.28 \mathrm{mmHg}$. These pressure results suggest there may be a benefit to reducing and/or eliminating glaucoma medications preoperatively to allow the pressure to temporarily rise. Given the results of this study, this could enhance the effectiveness of the procedure, especially in patients with IOP in the mid-teens on multiple topical medications.
The use of the microbypass stent reduced the mean number of medications needed to control IOP in patients with OAG. Postoperatively, the mean decrease in topical glaucoma medications at 2 years postoperatively was 0.58 less medications, with $63 \%$ of patients completely off medications. The results in this study are similar to those in other studies that monitored glaucoma medications used after cataract surgery and microbypass stent implantation. ${ }^{6,79}$ Patient compliance continues to be a significant concern for most eye care providers; therefore, a goal is to keep patients off or reduce the burden of topical medications postoperatively. Furthermore, the reduction of chronic topical glaucoma medications may improve patients' ocular surface as these medications can induce corneal damage and inflammation. ${ }^{17}$

With regard to safety, patients receiving the microbypass stent are not at risk for late-onset complications associated with filtering surgeries such as bleb leak, bleb-related infection, or hypotony. Implantation of a microbypass stent in combination with cataract surgery may benefit patients by delaying or avoiding all together the complications associated with separate additional surgical intervention. Moreover, future surgical options for trabeculectomy or tube shunt are preserved since the conjunctiva has not been violated. In this study, $12.4 \%(\mathrm{n}=31)$ of patients experienced an IOP spike $\geq 15 \mathrm{mmHg}$ at some point postoperatively and all responded to topical therapy. Of the 350 eyes that were followed and evaluated, two required additional tube shunt surgery. Three other eyes underwent secondary glaucoma surgery, all of which were endocyclophotocoagulation.

Implantation of the microbypass stent in patients undergoing cataract surgery provided improvements in the 
management of elevated IOP, with a favorable safety profile and sustained reductions in IOP and medication. The microbypass stent reestablishes the trabecular outflow, and spares the conjunctiva, thus avoiding the risk of complications associated with filtering procedures. With no exclusion criteria, this study mimics the clinical use of the device and demonstrates that the implantation of a microbypass stent represents an effective therapeutic approach to patients with $\mathrm{OAG}$ undergoing cataract surgery by providing reduction in IOP and medication use.

\section{Acknowledgments}

Meetings: Presented at 2014 ASCRS Meeting, Boston, MA, USA April 25-29, 2014.

Presented at 2015 ASCRS Meeting, San Diego, CA, USA April 17-21, 2015.

Presented at 2016 ASCRS Meeting, New Orleans, LA, USA May 6-10, 2016.

Sources of public and private financial support: None.

\section{Disclosure}

Dr John P Berdahl is a speaker and consultant for Glaukos Corporation. Dr Justin Schweitzer is also a consultant for Glaukos. The authors report no other conflicts of interest in this work.

\section{References}

1. Quigley HA, Broman AT. The number of people with glaucoma worldwide in 2010 and 2020. Br J Ophthalmol. 2006;90(3):262-267.

2. Robin AL, Novack GD, Covert DW, Crockett RS, Marcic TS. Adherence in glaucoma: objective measurements of once-daily and adjunctive medication use. Am J Ophthalmol. 2007;144(4):533-540.

3. Gupta R, Patil B, Shah BM, Bali SJ, Mishra SK, Dada T. Evaluating eye drop instillation technique in glaucoma patients. J Glaucoma. 2012; 21(3):189-192.

4. Gedde SJ, Schiffman JC, Feuer WJ, Herndon LW, Brandt JD, Budenz DL. Three-year follow-up of the tube versus trabeculectomy study. Am J Ophthalmol. 2009;148(5):670-684.
5. Arriola-Villalobos P, Martinez-De-La-Casa JM, Diaz Valle D, Fernández-Pérez C, Garcia-Sanchez J, García-Feijoó J. Combined iStent trabecular micro-bypass stent implantation and phacoemulsification for coexistent open-angle glaucoma and cataract: a long-term study. Br J Ophthalmol. 2012;96(5):645-649.

6. Samuelson TW, Katz LJ, Wells JM, Duh YJ, Giamporcaro JE. Randomized evaluation of the trabecular micro-bypass stent with phacoemulsification in patients with glaucoma and cataract. Ophthalmology. 2011;118(3):459-467.

7. Spiegel D, Wetzel W, Neuhann T, et al. Coexistent primary openangle glaucoma and cataract: interim analysis of a trabecular microbypass stent and concurrent cataract surgery. Eur J Ophthalmol. 2009;19(3):393-399.

8. SooHoo JR, Seibold LK, Radcliffe NM, Kahook MY. Minimally invasive glaucoma surgery: current implants and future innovations. Can J Ophthalmol. 2014;49(6):528-533.

9. Saheb H, Ahmed II. Micro-invasive glaucoma surgery: current perspectives and future directions. Curr Opin Ophthalmol. 2012;23(2):96-104.

10. Bahler CK, Smedley GT, Zhou J, Johnson DH. Trabecular bypass stents decrease intraocular pressure in cultured human anterior segments. $\mathrm{Am}$ J Ophthalmol. 2004;138(6):988-994.

11. Fea AM. Phacoemulsification versus phacoemulsification with microbypass stent implantation in primary open-angle glaucoma: randomized double-masked clinical trial. J Cataract Refract Surg. 2010;36(3):407-412.

12. Craven ER, Katz LJ, Wells JM, Giamporcaro JE; iStent Study Group. Cataract surgery with trabecular micro-bypass stent implantation in patients with mild-to-moderate open-angle glaucoma and cataract: two-year follow-up. J Cataract Refract Surg. 2012;38(8): 1339-1345.

13. Heijl A, Leske MC, Bengtsson B, Hyman L, Bengtsson B, Hussein M. Reduction of intraocular pressure and glaucoma progression: results from the early manifest glaucoma trial. Arch Ophthalmol. 2002; 120(10):1268-1279.

14. Hayashi K, Hayashi H, Nakao F, Hayashi F. Effect of cataract surgery on intraocular pressure control in glaucoma patients. $J$ Cartaract Refract Surg. 2001;27(11):1779-1786.

15. Kim DD, Doyle JW, Smith MF. Intraocular pressure reduction following phacoemulsification cataract extraction with posterior chamber lens implantation in glaucoma patients. Ophthalmic Surg Lasers. 1999; 30(1):37-40.

16. Poley BJ, Lindstrom RL, Samuelson TW. Long-term effects of phacoemulsification with intraocular lens implantation in normotensive and ocular hypertensive eyes. J Cartaract Refract Surg. 2008;34(5): $735-742$.

17. Noecker RJ, Herrygers LA, Anwaruddin R. Corneal and conjunctival changes caused by commonly used glaucoma medications. Cornea. 2004;23(5):490-495.
Clinical Ophthalmology

\section{Publish your work in this journal}

Clinical Ophthalmology is an international, peer-reviewed journal covering all subspecialties within ophthalmology. Key topics include: Optometry; Visual science; Pharmacology and drug therapy in eye diseases; Basic Sciences; Primary and Secondary eye care; Patient Safety and Quality of Care Improvements. This journal is indexed on Submit your manuscript here: http://www.dovepress.com/clinical-ophthalmology-journal

\section{Dovepress}

PubMed Central and CAS, and is the official journal of The Society of Clinical Ophthalmology (SCO). The manuscript management system is completely online and includes a very quick and fair peer-review system, which is all easy to use. Visit http://www.dovepress.com/ testimonials.php to read real quotes from published authors. 